Trauma Surgery $\&$ Acute Care Open

\title{
Management of splenic platelet sequestration in idiopathic thrombocytopenic purpura
}

\author{
Lindsay Anne Sceats 조 , Kelsey Lipman, David Spain
}

Department of Surgery, Stanford University, Stanford, California, USA

Correspondence to Dr David Spain; dspain@ stanford.edu

\section{SURGICAL DILEMMA}

A patient in their $40 \mathrm{~s}$ presented to the emergency department with 3 weeks of diffuse itching, epistaxis, oral ulcers, gum bleeding, petechiae and ecchymoses (figure 1). Medical history was notable for hypertension. The patient denied any recent illnesses, new medications or recent vaccinations. The patient denied any B symptoms including fevers, night sweats or weight loss. Family history was notable for a maternal cousin and uncle with thrombocytopenia requiring intervention.

Laboratory workup was notable for white blood coun (WBC) 8.7, hemoglobin 17, platelets $<2$, lactate dehydrogenase (LDH) 275, erythrocyte sedimentation rate (ESR) 33, and Coomb's direct antiglobulin test (DAT) + (anti-A IgG). Antinuclear antibody (ANA), HIV, hepatitis B and C, and COVID-19 were negative. CT abdomen/pelvis did not demonstrate any hepatosplenomegaly. Peripheral smear was notable for an absence of platelets and increased neutrophils, monocytes and lymphocytes. There was no significant dysplasia or blasts. The patient was treated for presumed idiopathic thrombocytopenic purpura (ITP) with intravenous immunoglobulin (IVIG) and pulse-dose intravenous steroids. The platelet count initially improved, but the response was not sustained, and the patient was transferred to our tertiary care institution for further management.

On transfer to our institution, additional hematological and rheumatological workup was pursued, which remained consistent with ITP. Plateletreactive antibodies were detected in the patient's serum against glycoprotein IIb/IIIa. Bone marrow biopsy was grossly normal, with an appropriate increase in the number of megakaryocytes without evidence of hematolymphoid malignancy.

The patient continued treatment with repeat IVIG and intravenous steroids. Romiplostim, a thrombopoetin receptor agonist (TPO-RA), was added as an additional second-line therapy. However, platelet count remained $<5$ and did not respond to further platelet transfusions. The patient was classified as having severe refractory ITP, and general surgery was consulted for further recommendations.

\section{WHAT WOULD YOU DO?}

employer(s)) 2021. Re-use permitted under CC BY-NC. No commercial re-use. See rights and permissions. Published by BMJ.

To cite: Sceats LA, Lipman K Spain D. Trauma Surg Acute Care Open 2021:6:e000693.
A. Continue medical management.

B. Angiography and embolization.

C. Laparoscopic splenectomy.

D. Open splenectomy.

WHAT WE DID AND WHY

C. Laparoscopic splenectomy
The patient was counseled regarding alternative treatment options including rituximab, fostamatinib or splenectomy. Current practice recommendations from the American Society of Hematology recognize rituximab, TPO-RAs and splenectomy as valid second-line therapies for ITP, with patient education and shared decision making encouraged to choose between these options. While limited data support partial splenic embolization as an alternative to splenectomy, splenic embolization has not yet been incorporated into most mainstream clinical practice recommendations.

Rituximab reduces the number of $\mathrm{B}$ cells producing antiplatelet antibodies, thereby raising platelet counts. The short-term response rate for rituximab is approximately $60 \%$, with approximately $25 \%$ of patients maintaining a durable rise in platelet count at 5 years. TPO-RA therapies induce platelet production by activating TPO receptors on megakaryocytes. Approximately 30\% of patients maintain a sustained durable response in platelets after tapering TPO-RA therapy, while others require long-term TPO-RA therapy. Splenectomy removes the primary site of platelet clearance and autoantibody production and has the highest rate of durable response (60\%-70\%) compared with other ITP therapies. Patients with a strong desire to avoid surgery may prefer a TPO-RA or rituximab. Patients who value achieving a durable response may prefer splenectomy.

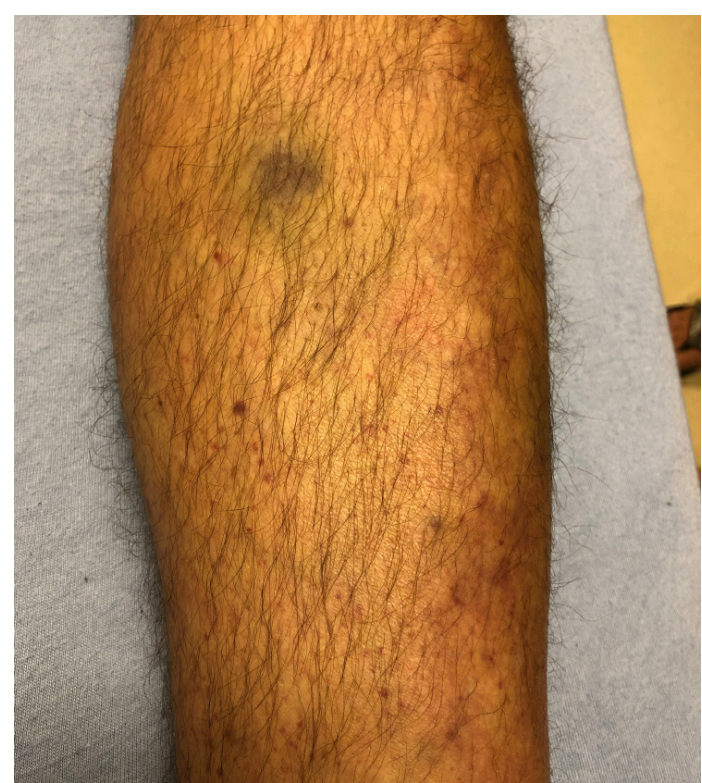

Figure 1 Lower extremity petechiae and ecchymoses at time of initial presentation. 


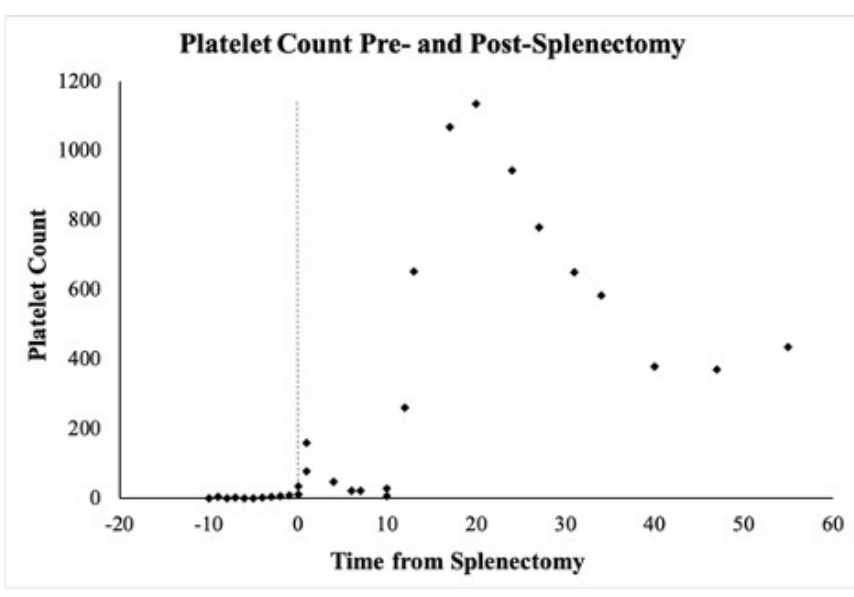

Figure 2 Presplenectomy and postsplenectomy platelet count.

Given that the patient had already failed a TPO-RA and hoped to return promptly to an active physical career, the patient was eager to proceed with treatment with a high likelihood of durable response. We ultimately recommended that the patient undergo splenectomy. As the spleen was not enlarged and the patient had no prior abdominal operations, we proceeded with laparoscopic splenectomy instead of open. Platelets were transfused preoperatively and intraoperatively, with a goal platelet count $>10$ at the time of operation.

The patient was placed in the right lateral decubitus position with the table flexed and in reverse trendelenberg. We placed three $5 \mathrm{~mm}$ port sites along with a $12 \mathrm{~mm}$ port for extraction along the left costal margin. The spleen was identified, and the splenocolic ligament was divided to mobilize the splenic flexure of the colon and the lower pole of the spleen. Lateral peritoneal attachments, the splenorenal ligament, short gastric vessels and the remaining gastrosplenic were divided in a similar manner. The splenic hilum was visualized, dissected off of the pancreatic tail and divided using the $45 \mathrm{~mm}$ Endo GIA stapler. The 12 $\mathrm{mm}$ port was upsized to a $15 \mathrm{~mm}$ port to place the spleen in an endoscopic retrieval bag. The spleen was removed in piecemeal after morcellation, taking care to prevent spillage. The field was inspected for hemostasis, and fascia and skin were closed. Postoperatively, the patient was transferred to the ward for further recovery.

The platelets rapidly recovered postoperatively. Preoperative and postoperative platelet counts are shown in figure 2 . The patient was discharged home on POD1 on a prednisone taper and did require one postoperative dose of romiplostim prior to platelet stabilization. At 2-month postoperative follow-up, the patient demonstrated a sustained platelet response to splenectomy, with platelet count stabilizing near 430 . The patient continues to follow with hematology to monitor for ITP relapse.

Contributors LAS and KL were responsible for literature and case review, manuscript drafting and manuscript revisions. DS was responsible for project conception and manuscript revisions. Both authors approve of the final manuscript version.

Funding The authors have not declared a specific grant for this research from any funding agency in the public, commercial or not-for-profit sectors.

Competing interests None declared.

Patient consent for publication Not required.

Provenance and peer review Not commissioned; internally peer reviewed.

Open access This is an open access article distributed in accordance with the Creative Commons Attribution Non Commercial (CC BY-NC 4.0) license, which permits others to distribute, remix, adapt, build upon this work non-commercially, and license their derivative works on different terms, provided the original work is properly cited, appropriate credit is given, any changes made indicated, and the use is non-commercial. See: http://creativecommons.org/licenses/by-nc/4.0/.

ORCID ID

Lindsay Anne Sceats http://orcid.org/0000-0002-4959-4095 